\title{
Preventive Effects of the Chinese Herbal Medicine Prescription Tangkuei Decoction for Frigid Extremities on Sciatic Neuropathy in Streptozotocin-Induced Diabetic Rats
}

\author{
Pengsong Liu, Yuanyuan Bian, Hong Zhang, and Aiming Jia \\ Department of Traditional Chinese Medicine, Second Affiliated Hospital of Dalian Medical University, Dalian, Liaoning 116023, China \\ Correspondence should be addressed to Aiming Jia; jiaam200310@163.com
}

Received 3 November 2015; Revised 24 January 2016; Accepted 1 February 2016

Academic Editor: Barbara Swanson

Copyright (c) 2016 Pengsong Liu et al. This is an open access article distributed under the Creative Commons Attribution License, which permits unrestricted use, distribution, and reproduction in any medium, provided the original work is properly cited.

Ischemia and hypoxia are important physiological changes in diabetic peripheral neuropathy (DPN). Chinese herbal medicine prescription Tangkuei Decoction for Frigid Extremities (TDFE) is useful for increasing blood flow. To help determine whether TDFE could protect the peripheral nerves of diabetic patients from the degeneration caused by high blood glucose, TDFE was administered to streptozotocin-induced diabetic rats for 6 or 12 weeks. Plantar thermal stimulation reaction time thresholds, sciatic nerve conduction velocities, and the levels of HIF- $1 \alpha$ mRNA, HIF-1 $\alpha$ protein, VEGF protein, and the endothelial marker vWF in sciatic nerves were measured at the end of the sixth and twelfth weeks. The thermal thresholds and sciatic nerve conduction velocities of the rats differed after 12 weeks, and the sciatic nerves of the diabetic rats that were given TDFE displayed higher levels of HIF- $1 \alpha$ protein, VEGF protein, and HIF- $1 \alpha$ mRNA than those of the diabetic model rats. The results at 6 weeks differed from those at 12 weeks. These results suggest that the early preventive application of TDFE effectively delayed the development of DPN and that TDFE increased HIF- $1 \alpha$ mRNA levels in the sciatic nerves of diabetic rats through 12 weeks of treatment.

\section{Introduction}

Diabetes mellitus (DM) is prevalent worldwide, and neuropathy is its most disabling and serious complication [1]. Resulting in painful and insensitive extremities and neuropathic ulceration and amputation, diabetic peripheral neuropathy (DPN) is one of the most common complications of both type 1 and type 2 diabetes [2]. Diabetes is associated with the failure of various organs, especially the blood vessels [3], and ischemia and hypoxia are considered important contributing factors in the development of DPN [2,4]. The role of low blood perfusion of peripheral nerves in the pathogenesis of DPN deserves more attention. Decreased endoneurial blood flow is observed early in DPN, and oxygen supplementation or treatment with vasodilators has beneficial effects [5]. In addition, hindquarter ischemia and decreased vascular density are found in diabetic animals [6].

Hypoxia-inducible factor-1 (HIF-1) is found in all of the extant metazoan species that have been analyzed [7] and consists of HIF- $1 \alpha$ and HIF- $1 \beta$ subunits [8]. The transcriptional regulator HIF- $1 \alpha$ is the oxygen regulatory subunit of HIF-1 and the key factor in the HIF-1-mediated response to hypoxia. Under hypoxic conditions, the degradation of HIF- $1 \alpha$ is weakened, while its transcriptional activity is strengthened [9]. The increased active HIF-1 $\alpha$ localizes to the nucleus and combines with HIF- $1 \beta$, forming HIF-1, which is able to increase the expression of a series of target genes that improve the adaptability of cells and tissues to low-oxygen conditions [8]. The potent proangiogenic factor vascular endothelial growth factor (VEGF) stimulates the proliferation and migration of endothelial cells and the formation of new blood vessels by increasing vascular permeability and changing the composition of the extracellular matrix. In general, HIF-1 $\alpha$ and angiogenic growth factors, such as VEGF, are necessary for endothelial progenitor cell (EPC) recruitment to ischemic sites to achieve neovascularization [10].

For thousands of years, natural products for medicine and health have been very important [11], and clinical studies have demonstrated that Chinese herbal medicine (CHM) can be more effective than conventional medicine [12]. In addition, 
CHM has been approved for use in the treatment of DPN [13]. In China, a large number of clinical trials have demonstrated that the CHM prescription Tangkuei Decoction for Frigid Extremities (TDFE) can relieve the clinical symptoms of DPN. To date, no adverse health effects have been observed due to the clinical application of TDFE.

Clinical methods of diagnosing DPN are not objective or reproducible [14]. Thus, preventive administration of therapeutics deserves more attention. In the present study, the preventive effect of TDFE on DPN was investigated. We hypothesized that TDFE would be able to protect diabetic patients from the effects of DPN. The experiments were divided into two stages (6 weeks and 12 weeks) to evaluate chronic and acute-onset DPN. The plantar thermal stimulation reaction time threshold and nerve conduction velocity were used as neurophysiological measurements, and the endothelial marker von Willebrand factor (vWF) was used to estimate vasa nervorum density. The levels of HIF$1 \alpha$ and VEGF in sciatic nerves were also investigated as a first step in exploring the molecular mechanism of action of TDFE.

\section{Materials and Methods}

2.1. Animals. Fifty-five 6-week-old male Sprague-Dawley rats weighing $200 \pm 20 \mathrm{~g}$ were purchased from the Experimental Animal Center of Dalian Medical University. All of the rats were raised at $22 \pm 3^{\circ} \mathrm{C}$, with $50 \%$ humidity and a $12 \mathrm{~h}$ light/dark cycle. The rats were randomly divided into 6 groups one week after adaptive feeding: 7 rats in the 6 -week blank control $(6 \mathrm{wBC})$ group, 10 rats in the 6-week diabetic model (6wDM) group, 9 rats in the 6-week medicine prophylaxis (6wMP) group, 8 rats in the 12 -week blank control (12wBC) group, 11 rats in the 12 -week diabetic model (12wDM) group, and 10 rats in the 12 -week medicine prophylaxis (12wMP) group. During this period, one rat from the $12 \mathrm{wBC}$ group was removed from the experiment due to an accidentally injured toe. All of the experimental procedures were approved in advance by the Animal Care and Use Committee of Dalian Medical University and were performed in compliance with the National Institutes of Health Guidelines for the Care and Use of Laboratory Animals.

2.2. Materials and Instruments. The herbal components of TDFE, including Radix Angelicae Sinensis (traditional Chinese name (TCN): Danggui), Cassia Twig (TCN: Guizhi), Radix Paeonia Alba (TCN: Baishao), Asarum sieboldii Mig (TCN: Xixin), Radix liquiritiae (TCN: Gancao), Akebia quinata Decne. (TCN: Mutong), and Fructus Ziziphi Jujubae (TCN: Dazao), were purchased from the Pharmacy Department of the Second Affiliated Hospital of Dalian Medical University. The HIF- $\alpha$ (K377) polyclonal antibody, the VEGFA polyclonal antibody, and the vWF polyclonal antibody were purchased from Bioworld, Dalian Xinhua Biotechnology Co., Ltd., Dalian, China. The peroxidase-conjugated AffiniPure goat anti-rabbit $\operatorname{IgG}(\mathrm{H}+\mathrm{L})$ and DAB kit ZSGBBIO were purchased from Dalian Xinhua Biotechnology Co., Ltd., Dalian, China. The BCA Protein Assay Kit was purchased from Pierce, and the SDS-PAGE kit was purchased from Biotesh, Biotesh Biological \& Technology Co., Ltd., Beijing China. RNAiso Plus (9108) and the PrimeScript RT Reagent Kit with gDNA Eraser (RR047A) were purchased from TaKaRa Biotechnology Co., Ltd., Dalian, China. The Thermal-Tingling Apparatus (PL-200) and the biological function experiment system (BL-420F) were purchased from Taimeng, Chengdu Taimeng Software Co., Ltd., Chengdu, China. The BX51 multifunctional microscope was purchased from OLYMPUS Co., Ltd., Beijing, China. The electrophoresis systems (DYCZ 24DN and DYCZ 40D) were purchased from the Beijing Liuyi Instrument Plant, Beijing, China. The TaKaRa PCR Thermal Cycler Dice Real-Time System TP800 was purchased from TaKaRa Biotechnology Co., Ltd., Dalian, China.

2.3. Procedures. The four groups (6wDM, 6wMP, $12 \mathrm{wDM}$, and $12 \mathrm{wMP}$ ) of rats were fasted for 12 hours and then received a single intraperitoneal injection of streptozotocin (50 mg/kg body weight) in citrate buffer at $0.1 \mathrm{~mol} / \mathrm{L}, \mathrm{pH} 4.4$. After 72 hours, the glucose level of blood collected from the caudal vein was measured, and rats displaying glucose levels greater than $16.7 \mathrm{mmol} / \mathrm{L}$ were selected. Blood glucose was monitored once every other day. Rats with higher glucose levels were injected with insulin so that all of the rats had similar blood glucose levels. Establishment of the model failed in one rat in each of the $6 \mathrm{wDM}, 6 \mathrm{wMP}$, and $12 \mathrm{wDM}$ groups. Two rats in the $12 \mathrm{wDM}$ group, one in the $6 \mathrm{wMP}$ group, and one in the 12wMP group died due to extremely high glucose levels. Three rats (one each from the $6 \mathrm{wDM}$, $12 \mathrm{wDM}$, and $12 \mathrm{wMP}$ groups) were removed from the study because their blood glucose levels did not remain elevated during the experiment.

2.4. Drug Administration. TDFE was decocted in the Pharmacy Department of the Second Affiliated Hospital of Dalian Medical University. A unified composition proportion was set according to "Fang Ji Xue" (First Edition, 2013.1) published by the China Press of Traditional Chinese Medicine (Radix Angelicae Sinensis : Cassia Twig : Radix Paeonia Alba : Asarum sieboldii Mig: Radix liquiritiae: Akebia quinata Decne.: Fructus Ziziphi Jujuba $=4: 3: 3: 1: 2: 2: 10)$. The effective dosage of TDFE in humans is approximately $1.7 \mathrm{~g} / \mathrm{kg} / \mathrm{d}$. Rats require approximately 5.7 times the amount of a drug as patients, and intragastric administration requires double the amount needed for oral administration. Thus, a concentration of $1.6 \mathrm{~g}$ of crude drug in $1 \mathrm{~mL}$ of distilled water was used. The TDFE at a dosage of $12 \mathrm{~mL} / \mathrm{kg} / \mathrm{d}$ was administered to the rats in the $6 \mathrm{wMP}$ and $12 \mathrm{wMP}$ groups, while the other rats were given distilled water at the same dosage. Intragastric administration was sustained for 6 weeks in the $6 \mathrm{wBC}, 6 \mathrm{wDM}$, and $6 \mathrm{wMP}$ groups and for 12 weeks in the $12 \mathrm{wBC}, 12 \mathrm{wDM}$, and $12 \mathrm{wMP}$ groups. Stomach needles were replaced once weekly to protect the rats. One rat in the $6 \mathrm{wDM}$ group died due to an error in intragastric administration.

2.5. Plantar Testing. By the end of the 6 th week, the plantar thermal stimulation reaction time thresholds of the rats in 
the $6 \mathrm{wBC}, 6 \mathrm{wDM}$, and $6 \mathrm{wMP}$ groups (the $6 \mathrm{w}$ rats) were tested. After the apparatus was turned on, it was preheated for one minute. The stop time was set to 30 seconds, and the laser intensity was set to $50 \%$. The rats were placed in the upper boxes until they were motionless. The heat radiation box on the ground floor was moved so that the emission hole was aligned with the center part of the rats' forefeet. The host computer started counting automatically as soon as the launch button was pressed, and timing was discontinued when the rats raised their tested feet. The two rear feet were tested as well, and average results were determined. The thresholds of the rats in the $12 \mathrm{wBC}, 12 \mathrm{wDM}$, and $12 \mathrm{wMP}$ groups (the $12 \mathrm{w}$ rats) were measured in the same way at the end of the 12 th week.

2.6. Electrophysiology. At the end of the 6th week, the sciatic nerve conduction velocities (SNCVs) of the $6 \mathrm{w}$ rats were measured in accordance with published procedures [15]. After the intraperitoneal injection of $10 \%$ chloral hydrate $(3 \mathrm{~mL} / \mathrm{kg})$, the rats were fixed on the operating table in the prone position at a temperature of $20 \pm 1^{\circ} \mathrm{C}$. The stimulating electrode was placed in the sciatic notch, where the sciatic nerve exits the pelvis, and the recording electrode was placed in the ankle, through which the sciatic nerve passes. The reference electrode was placed between them. A single square wave pulse with a width of $0.1 \mathrm{~ms}$ was used. The stimulus intensity, which permitted the presence or absence of an action potential, was varied to determine the stimulus threshold. An intensity of 1.5 times the stimulation threshold was used, and the nerve potential waveform was recorded. The period from the beginning of the stimulation to the occurrence of an action potential was defined as the conduction time of the excitatory signal. The right rear leg of each rat was straightened to create an angle of $45^{\circ}$ with the spine. Electroneuronography was performed using a BL-420F biological function experiment system (Figure 1). The distance between the stimulating electrode and the recording electrode was also measured. Then, the SNCV was determined using the formula $S N C V=$ distance between the two electrodes/conduction time of the excitatory signal. The measurements were repeated three times and the results were averaged. The $12 \mathrm{w}$ rats were tested in the same way at the end of the 12 th week.

2.7. Immunohistochemistry. Six weeks after the diabetes model was established, $10 \%$ chloral hydrate $(3 \mathrm{~mL} / \mathrm{kg})$ was injected into the $6 \mathrm{w}$ rats. The sciatic nerves (approximately $1 \mathrm{~cm}$ ) were excised, fixed in $4 \%$ paraformaldehyde for $24 \mathrm{~h}$, and embedded in paraffin. Subsequently, 3- $\mu \mathrm{m}$ thick sections were prepared. Endogenous peroxidases were inactivated by $3 \% \mathrm{H}_{2} \mathrm{O}_{2}$ for $20 \mathrm{~min}$, and the antigen was repaired in $\mathrm{CB}$ buffer. The HIF-1 $\alpha$, VEGF, and vWF antibodies (1:50 dilution) were applied to the sections at $37^{\circ} \mathrm{C}$ for 1 hour and subsequently at $4^{\circ} \mathrm{C}$ for one night. The next morning, peroxidase-conjugated AffiniPure goat anti-rabbit IgG was applied at $37^{\circ} \mathrm{C}$ for 30 minutes. DAB was used for visualization, and the reaction time was controlled under a microscope. After sufficient color had developed, the specimens were dehydrated and sealed. PBS was used as a negative control. Photos were taken using a multifunctional microscope and analyzed with Image-Pro Plus.

2.8. Western Blotting. The sciatic nerves were placed in liquid nitrogen as soon as they were extracted from the rats and were dissected, desheathed, and homogenized in ice-cold lysis buffer $(1 \mu \mathrm{g}$ of nerve tissue was added to $10 \mu \mathrm{L}$ of RIPA) supplemented with protease inhibitors ( $1 \mathrm{~mL}$ of RIPA required $10 \mu \mathrm{L}$ of $\mathrm{PMSF}$ ). The homogenates were allowed to stand for 30 minutes and then centrifuged at 10,000 rpm for 15 minutes at $4^{\circ} \mathrm{C}$. The supernatants were collected, and the BCA Protein Assay Kit was used to ensure that all of the samples had the same protein concentration. The samples were mixed with loading buffer supernatants and placed in water at $95^{\circ} \mathrm{C}$ for $10 \mathrm{~min}$. Tissue lysates ( $32 \mu \mathrm{g}$ of protein) were subjected to SDS-PAGE ( $8 \%$ acrylamide gels) at $120 \mathrm{~V}$ for 55 minutes and then electrotransferred at $250 \mathrm{~mA}$ for $120 \mathrm{~min}$ onto PVDF membranes. The membranes were blocked with $5 \%$ nonfat dry milk for 1 hour and incubated with the HIF-1 $\alpha$ (K377) polyclonal antibody or the VEGF-A polyclonal antibody at $4^{\circ} \mathrm{C}$ for one night. After the membranes were washed, they were incubated with peroxidase-conjugated AffiniPure goat anti-rabbit $\operatorname{IgG}(\mathrm{H}+\mathrm{L})$. The antigen-antibody complexes were visualized by enhanced chemiluminescence detection, and the protein bands were analyzed with Image $\mathrm{J} 2 \mathrm{x}$.

2.9. Real-Time PCR. After total RNA was extracted from the sciatic nerves and assessed by electrophoresis, it was used as a template to create CDNA for PCR. The following primers were used: TCTAGTGAACAGGATGGAATGGAG (sense) and TCGTAACTGGTCAGCTGTGGTAA (antisense) for HIF- $1 \alpha$; and GGAGATTACTGCCCTGGCTCCTA (sense) and GACTCATCGTACTCCTGCTTGCTG (antisense) for $\beta$-actin. Using SYBR Green I, the cDNA that was obtained from the reverse transcription of the total RNA $(500 \mathrm{ng} / \mu \mathrm{L})$ extracted from the $6 \mathrm{wBC}$ rats was used as a standard to obtain standard curves for HIF- $1 \alpha$ and $\beta$-actin. Each sample (100 ng) was compared with the standard curves to determine the relative level of HIF- $1 \alpha$ mRNA.

2.10. Statistical Analysis. SPSS 13.0 was used, and all of the numerical data are expressed as the $x \pm s$. The significance of differences between groups was analyzed by single-factor analysis of variance. Student's $t$-test was used for comparisons between two groups. The correlation of two variables was analyzed by Pearson's test. Significance was defined at $P<$ 0.05 .

\section{Results}

3.1. Plantar Thermal Stimulation Reaction Time Threshold. As shown in Table 1, the plantar thermal stimulation reaction time thresholds of the rats in the $6 \mathrm{wBC}, 6 \mathrm{wDM}$, and $6 \mathrm{wMP}$ groups did not significantly differ $(P>0.05)$. Compared to the rats in the $12 \mathrm{wBC}$ group, the rats in the $12 \mathrm{wDM}$ and 12wMP groups exhibited longer plantar thermal stimulation reaction times $(P<0.05)$. In addition, the reaction time 


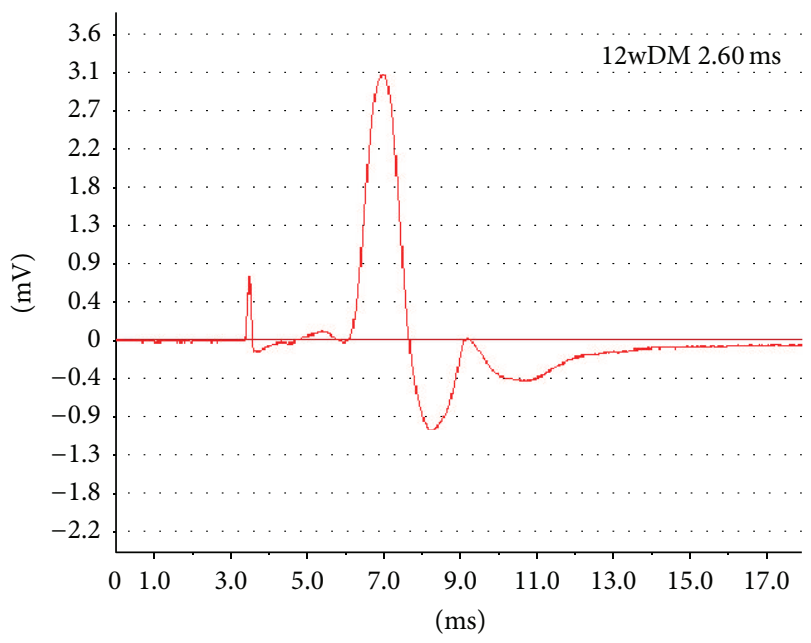

(a)

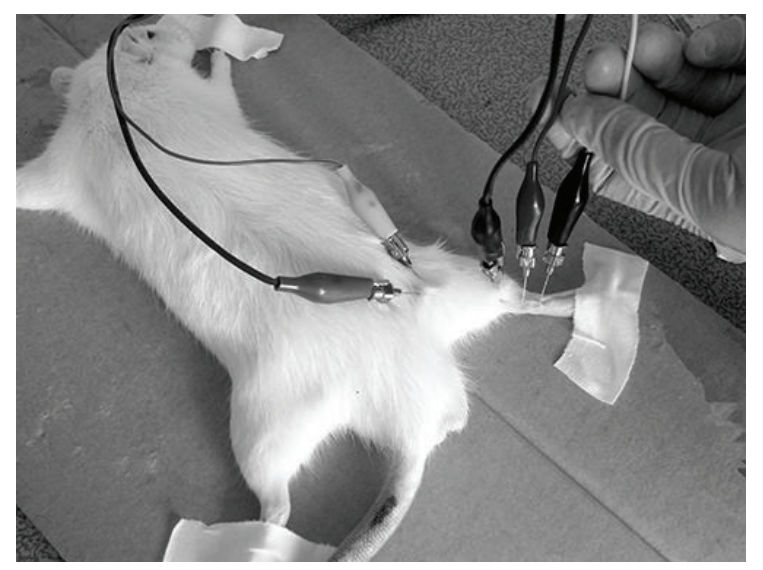

(c)

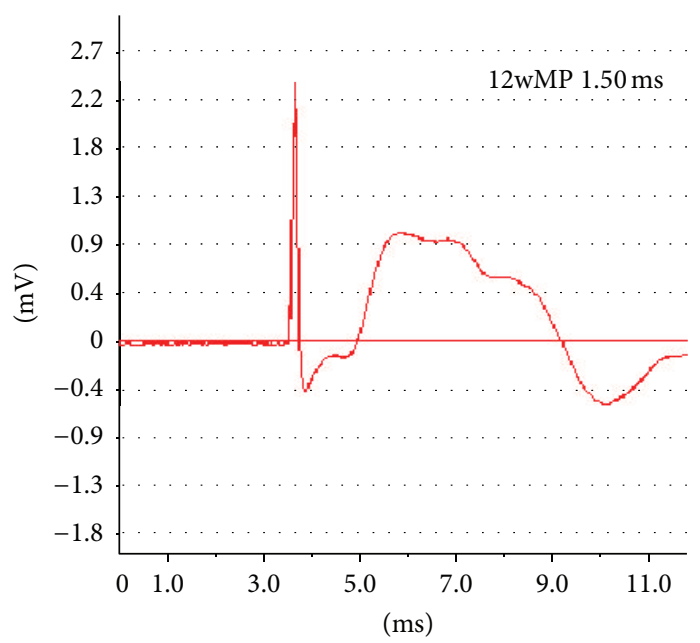

(b)

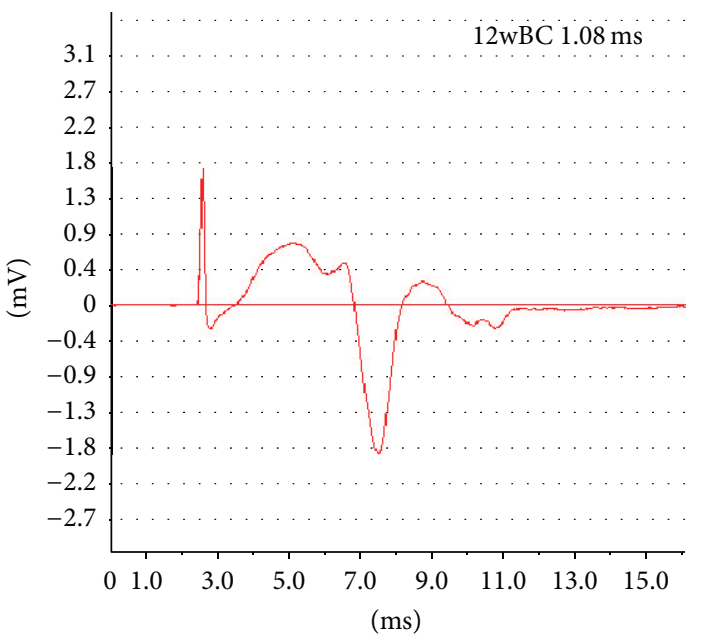

(d)

FIGURE 1: Testing of excitatory signal conduction time in sciatic nerves. (a) Electroneuronography of a rat from the 12-week diabetic model group. (b) Electroneuronography of a rat from the 12-week medicine prophylaxis group. (c) The site of conduction velocity determination. (d) Electroneuronography of a rat from the 12-week blank control group. The abscissa represents the conduction time (ms), and the ordinate represents the electrical potential $(\mathrm{mV})$. ms: millisecond. $\mathrm{mV}$ : millivolt.

TABLE 1: Plantar thermal stimulation reaction time thresholds of the rats.

\begin{tabular}{lcccccc}
\hline Groups & $6 w B C$ & $6 w D M$ & $6 w M P$ & $12 w B C$ & $12 w D M$ & $12 w M P$ \\
\hline Thresholds (s) & $10.78 \pm 2.83$ & $12.53 \pm 2.74$ & $11.50 \pm 2.50$ & $10.74 \pm 1.54$ & $25.19 \pm 1.82^{*}$ & $17.01 \pm 3.20^{* \#}$ \\
\hline
\end{tabular}

${ }^{*} P<0.05$ versus the $12 \mathrm{wBC}$ group. ${ }^{\#} P<0.05$ versus the $12 \mathrm{wDM}$ group. $6 \mathrm{wBC}$ : 6 -week blank control group. $6 \mathrm{wDM}$ : 6 -week diabetic model group. $6 \mathrm{wMP}$ : 6 week medicine prophylaxis group. 12wBC: 12 -week blank control group. 12wDM: 12-week diabetic model group. 12wMP: 12-week medicine prophylaxis group. (s): seconds.

of the $12 \mathrm{wDM}$ rats was longer than that of the $12 \mathrm{wMP}$ rats $(P<0.05)$.

3.2. Sciatic Nerve Conduction Velocity. There were no significant differences in sciatic nerve conduction velocity among the rats in the $6 \mathrm{wBC}, 6 \mathrm{wDM}$, and $6 \mathrm{wMP}$ groups $(P>0.05)$. Compared to that of the rats in the $12 \mathrm{wBC}$ group, the sciatic nerve conduction velocity of the rats in the $12 \mathrm{wDM}$ and 12wMP groups was slower $(P<0.05)$, and the conduction velocity of the $12 \mathrm{wDM}$ rats was slower than that of the $12 \mathrm{wMP}$ rats $(P<0.05)$. The results are described in Table 2 .

3.3. HIF-1 $\alpha$ mRNA, HIF-1 $\alpha$ Protein, and VEGF Protein Levels. There were no significant differences in HIF- $1 \alpha$ mRNA levels among the $6 \mathrm{w}$ groups $(P>0.05)$. Compared to the levels in the nerves of the $6 \mathrm{wBC}$ groups, HIF- $1 \alpha$ and VEGF protein levels in the sciatic nerves of the $6 \mathrm{wDM}$ and $6 \mathrm{wMP}$ groups were higher $(P<0.05)$, while the levels of HIF-1 $\alpha$ and 
TABLE 2: Sciatic nerve conduction velocities (SNCVs) of the rats.

\begin{tabular}{lcccccc}
\hline Groups & $6 w B C$ & $6 w D M$ & $6 w M P$ & $12 w B C$ & $12 w D M$ & $12 w M P$ \\
\hline SNCV $(\mathrm{m} / \mathrm{s})$ & $48.03 \pm 4.96$ & $44.37 \pm 5.17$ & $46.33 \pm 3.98$ & $48.68 \pm 5.63$ & $29.69 \pm 3.31^{*}$ & $38.66 \pm 3.94^{* \#}$ \\
\hline
\end{tabular}

${ }^{*} P<0.05$ versus the $12 \mathrm{wBC}$ group. ${ }^{\#} P<0.05$ versus the $12 \mathrm{wDM}$ group. $6 \mathrm{wBC}$ : 6-week blank control group. $6 \mathrm{wDM}$ : 6-week diabetic model group. $6 \mathrm{wMP}$ : 6 week medicine prophylaxis group. 12wBC: 12-week blank control group. 12wDM: 12-week diabetic model group. 12wMP: 12-week medicine prophylaxis group. $(\mathrm{m} / \mathrm{s})$ : meters/second.

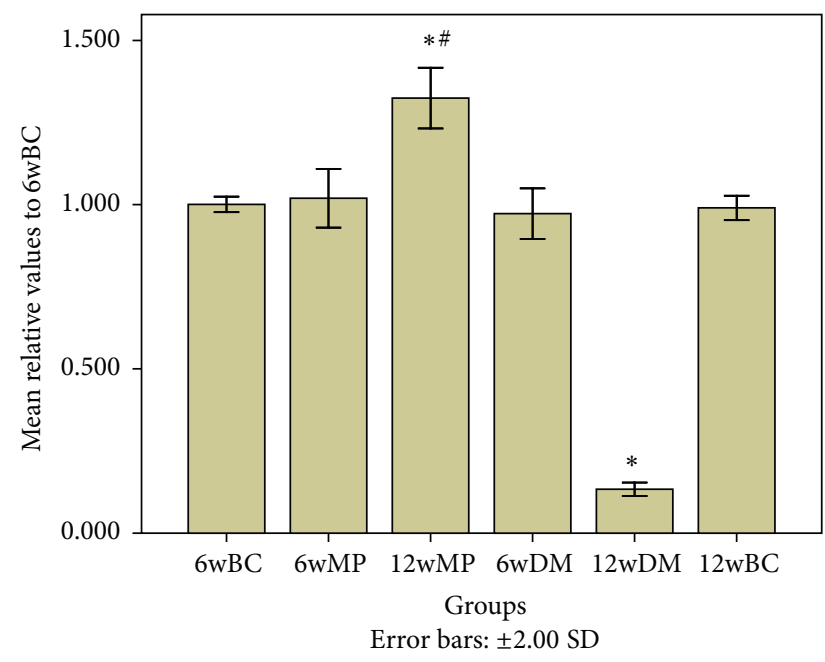

Figure 2: Relative levels of HIF- $1 \alpha$ mRNA. ${ }^{*} P<0.05$ versus the $12 \mathrm{wBC}$ group. ${ }^{*} P<0.05$ versus the $12 \mathrm{wDM}$ group. $6 \mathrm{wBC}$ : 6-week blank control group. 6wMP: 6-week medicine prophylaxis group. 12wMP: 12-week medicine prophylaxis group. 6wDM: 6week diabetic model group. 12wDM: 12-week diabetic model group. 12wBC: 12-week blank control group.

VEGF protein in the 6wMP sciatic nerves were lower than those in the $6 \mathrm{wDM}$ nerves $(P<0.05)$. Compared to those of the $6 \mathrm{wDM}$ group, the sciatic nerves of the $12 \mathrm{wDM}$ group expressed less HIF-1 $\alpha$ mRNA, HIF-1 $\alpha$ protein, and VEGF protein $(P<0.05)$. The 12wMP nerves showed higher levels of HIF- $1 \alpha$ mRNA, HIF- $1 \alpha$ protein, and VEGF protein than the 6WMP nerves $(P<0.05)$. There were no significant differences in the levels of HIF-1 $\alpha$ protein between $12 \mathrm{wBC}$ and $12 \mathrm{wDM}$ groups $(P>0.05)$. Compared to those of the $12 \mathrm{wBC}$ rats, the sciatic nerves of the $12 \mathrm{wDM}$ rats expressed less HIF- $1 \alpha$ mRNA and VEGF protein $(P<0.05)$. In contrast, the sciatic nerves of the 12wMP group expressed significantly more HIF- $1 \alpha$ mRNA, HIF- $1 \alpha$ protein, and VEGF protein than those of the $12 \mathrm{wBC}$ group $(P<0.05)$. Compared to those in the nerves of the $12 \mathrm{wDM}$ rats, the levels of HIF-1 $\alpha$ mRNA, HIF- $1 \alpha$ protein, and VEGF protein in the sciatic nerves of the 12wMP rats were significantly higher $(P<0.05)$. The VEGF protein levels in the sciatic nerves depended on the HIF-1 $\alpha$ protein levels, as reflected by a statistically significant correlation $(r=0.945, P<0.05)$ (Figures $2-5)$.

3.4. HIF-1 $\alpha, V E G F$, and $v W F$ Expression. HIF-1 $\alpha$-positive cells were not found in all of the groups. VEGF expression was found in small and medium neurons as well as in the membranes, axons, and myelin sheath of the sciatic nerves.
As shown in Figures 6 and 7, the expression of VEGF in the $6 \mathrm{wDM}$ and $6 \mathrm{wMP}$ groups was higher than that in the $6 \mathrm{wBC}$ group $(P<0.05)$, and more VEGF was expressed in the $6 \mathrm{wDM}$ group than in the $6 \mathrm{wMP}$ group $(P<0.05)$. The expression of VEGF in the $12 \mathrm{wDM}$ group was lower than that in the $12 \mathrm{wBC}$ group $(P<0.05)$, while more VEGF was expressed in the 12wMP group than in the $12 \mathrm{wBC}$ group $(P<$ $0.05)$. vWF immunoreactivity was detected in endoneurial and epineurial vessels. As shown in Figures 8 and 9, the expression of $\mathrm{vWF}$ in the $6 \mathrm{wDM}$ and $6 \mathrm{wMP}$ groups was lower than that in the $6 \mathrm{wBC}$ group $(P<0.05)$, and less vWF was expressed in the $6 \mathrm{wDM}$ group than in the $6 \mathrm{wMP}$ group $(P<0.05)$. The expression of $\mathrm{vWF}$ in the $12 \mathrm{wDM}$ and $12 \mathrm{wMP}$ groups was lower than that in the $12 \mathrm{wBC}$ group $(P<0.05)$, while more $\mathrm{vWF}$ was expressed in the $12 \mathrm{wMP}$ group than in the $12 \mathrm{wDM}$ group $(P<0.05)$.

\section{Discussion}

The present study clearly demonstrated that TDFE relieved the decrease in plantar thermal sensation and sciatic nerve conduction velocity as well as vasa nervorum injury in diabetic rats. TDFE delayed the development of DPN, and its preventive function was closely associated with HIF- $1 \alpha$ and VEGF. No adverse health effects of TDFE administration were observed throughout the course of the experiments.

The HIF- $1 \alpha$ subunit is virtually undetectable under normoxic conditions due to its very short half-life of less than $5 \mathrm{~min}$; it is rapidly degraded by the ubiquitin-proteasome pathway [16]. Because immunohistochemistry was performed under normoxic conditions, cells expressing HIF- $1 \alpha$ were not found in all of the groups. vWF is produced in endothelium, megakaryocytes and subendothelial connective tissue [17]. It was used as an endothelial marker to identify endoneurial and epineurial vessels in sciatic nerves. The low expression of $\mathrm{vWF}$ in the $6 \mathrm{wDM}$ rats and $12 \mathrm{wDM}$ rats indicates that the vasa nervorum of the rats were damaged by the diabetes. The increased expression of vWF in the $6 \mathrm{wMP}$ rats and $12 \mathrm{wMP}$ rats suggests that the application of TDFE relieved the ischemia and hypoxia of the sciatic nerves. The ischemia-induced production of growth factors (including VEGF) has been clearly shown to be decreased in diabetic tissues and in hyperglycemia [18, 19]. Similar immunohistochemistry results were obtained for the sciatic nerves of the $12 \mathrm{wDM}$ rats.

Nerve regeneration requires the coordination of multiple cell types. According to Cattin et al. [20], macrophages are sensitive to hypoxia in peripheral nerves. Upon hypoxia, the transcription factor HIF- $1 \alpha$ is stabilized and initiates a transcriptional response that induces angiogenesis by upregulating VEGF. The increased expression of VEGF in macrophages 


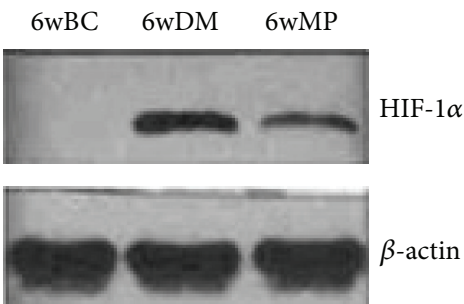

(a)

6wDM 6wBC 6wMP

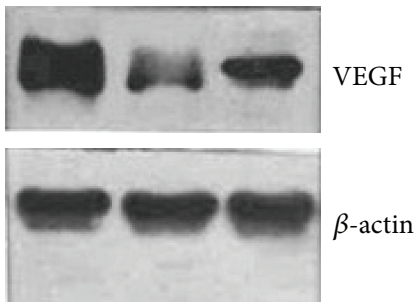

(e)

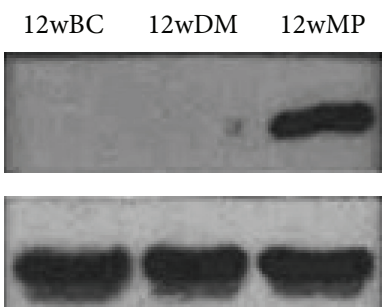

(b)

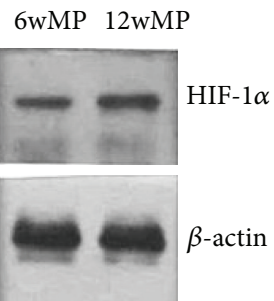

(c)

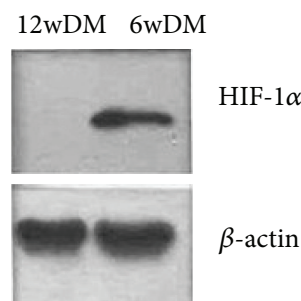

(d)

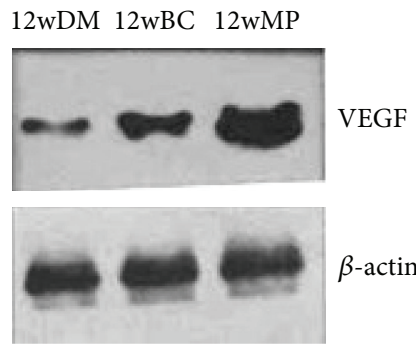

(f)

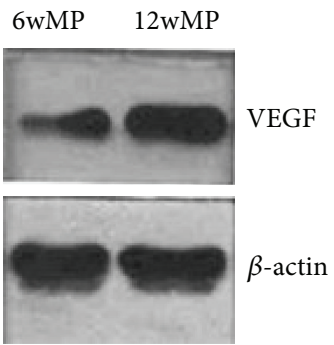

(g)

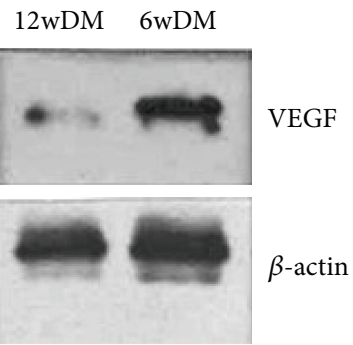

(h)

FIGURE 3: Western blot analysis of protein expression. (a) Comparison of HIF-1 $\alpha$ protein levels in the $6 \mathrm{wBC}, 6 \mathrm{wDM}$, and $6 \mathrm{wMP}$ groups. (b) Comparison of HIF- $1 \alpha$ protein levels in the $12 \mathrm{wBC}, 12 \mathrm{wDM}$, and $12 \mathrm{wMP}$ groups. (c) Comparison of HIF- $1 \alpha$ protein levels between the $6 \mathrm{wMP}$ and $12 \mathrm{wMP}$ groups. (d) Comparison of HIF-1 $\alpha$ protein levels between the $12 \mathrm{wDM}$ and $6 \mathrm{wDM}$ groups. (e) Comparison of VEGF protein levels in the $6 \mathrm{wBC}, 6 \mathrm{wDM}$, and $6 \mathrm{wMP}$ groups. (f) Comparison of VEGF protein levels in the $12 \mathrm{wBC}, 12 \mathrm{wDM}$, and $12 \mathrm{wMP}$ groups. (g) Comparison of VEGF protein levels between the 6wMP and 12wMP groups. (f) Comparison of VEGF protein levels between the 12wDM and 6wDM groups. 6wBC: 6-week blank control group. 6wDM: 6-week diabetic model group. 6wMP: 6-week medicine prophylaxis group. 12wBC: 12week blank control group. $12 \mathrm{wDM}$ : 12 -week diabetic model group. $12 \mathrm{wMP}$ : 12 -week medicine prophylaxis group. $\beta$-actin protein was used as an internal control.

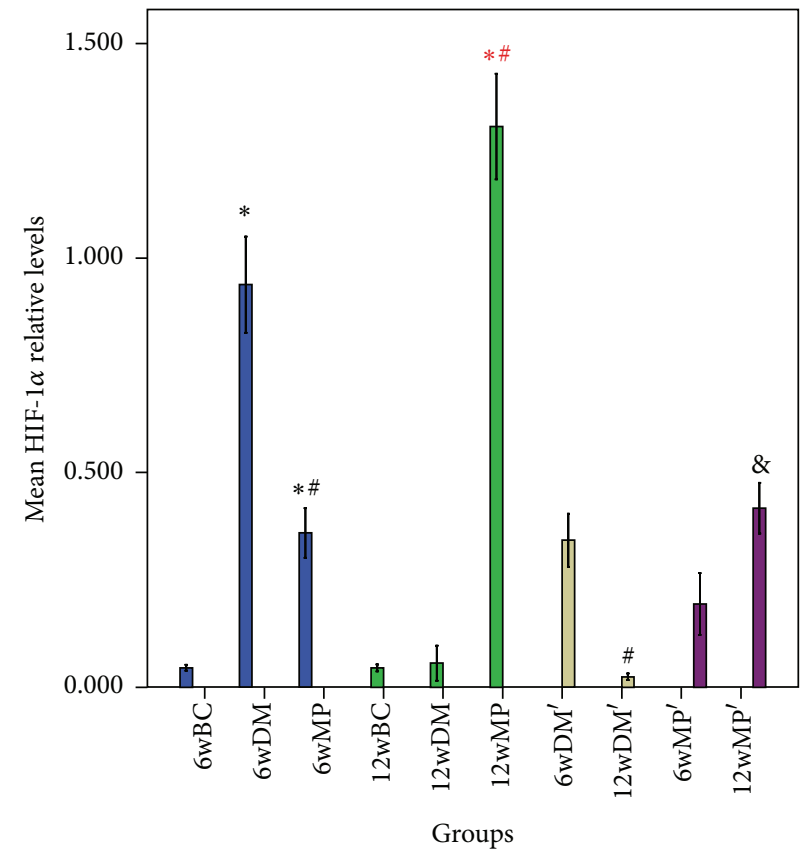

Error bars: $95.00 \% \mathrm{CI}$

Tests of HIF- $1 \alpha$

$\begin{array}{ll}\square \text { 6w HIF- } 1 \alpha & \square \text { DM HIF- } 1 \alpha \\ \square 12 \text { w HIF- } 1 \alpha & \square \text { MP HIF- } 1 \alpha\end{array}$

Figure 4: Western blot analysis of HIF- $1 \alpha$ protein expression. ${ }^{*} P<0.05$ versus the $6 \mathrm{wBC}$ group. ${ }^{\#} P<0.05$ versus the 6 wDM group. ${ }^{*} P<0.05$ versus the $12 \mathrm{wBC}$ group. ${ }^{\#} P<0.05$ versus the $12 \mathrm{wDM}$ group. ${ }^{\&} \mathrm{P}<0.05$ versus the $6 \mathrm{wMP}$ group. $6 \mathrm{w}$ HIF- $1 \alpha$ : comparison of HIF- $1 \alpha$ protein levels in the $6 \mathrm{wBC}, 6 \mathrm{wDM}$, and $6 \mathrm{wMP}$ groups. $12 \mathrm{w}$ HIF-1 $\alpha$ : comparison of HIF-1 $\alpha$ protein levels in the $12 \mathrm{wBC}, 12 \mathrm{wDM}$, and $12 \mathrm{wMP}$ groups. DM HIF- $1 \alpha$ : comparison of HIF- $1 \alpha$ protein levels between the $6 \mathrm{wDM}$ and $12 \mathrm{wDM}$ groups. MP HIF-1 $\alpha$ : comparison of HIF- $1 \alpha$ protein levels between the 6wMP and 12wMP groups. 6wBC: 6-week blank control group. 6wDM: 6-week diabetic model group. 6wMP: 6-week medicine prophylaxis group. $12 \mathrm{wBC}$ : 12 -week blank control group. 12wDM: 12-week diabetic model group. 12wMP: 12-week medicine prophylaxis group. 


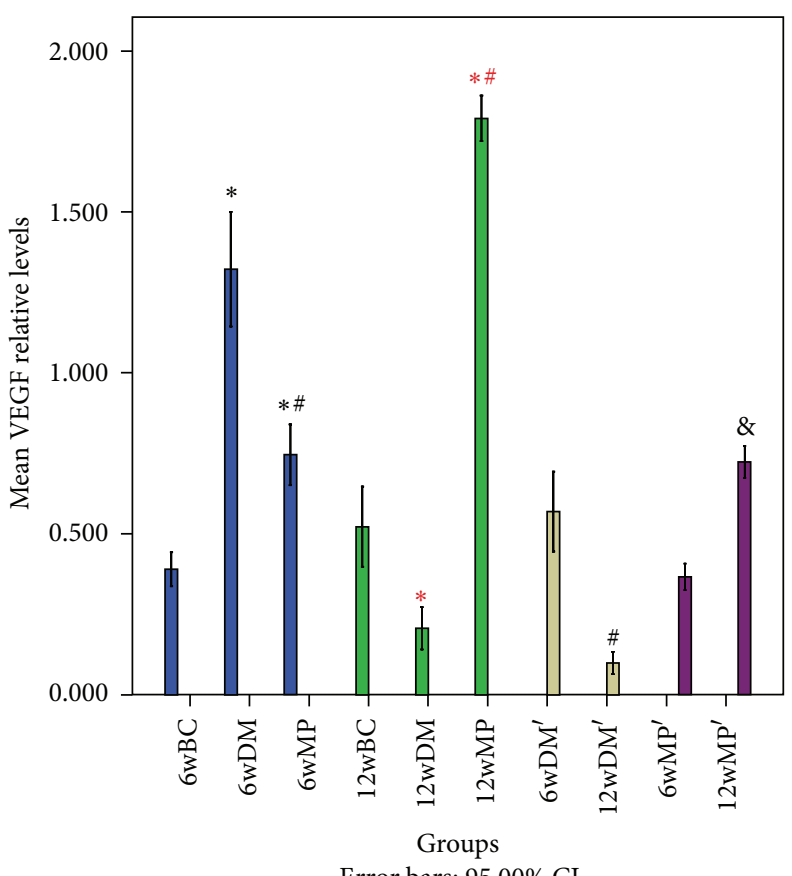

$\begin{array}{ll}\text { Tests of VEGF } & \\ \square \text { 6w VEGF } & \square \text { DM VEGF } \\ \square \text { 12w VEGF } & \square \text { MP VEGF }\end{array}$

Figure 5: Western blot analysis of VEGF protein expression. ${ }^{*} P<0.05$ versus the $6 \mathrm{wBC}$ group. ${ }^{*} P<0.05$ versus the $6 \mathrm{wDM}$ group. ${ }^{*} P<0.05$ versus the $12 \mathrm{wBC}$ group. ${ }^{\#} P<0.05$ versus the $12 \mathrm{wDM}$ group. ${ }^{\circledR} P<0.05$ versus the $6 \mathrm{wMP}$ group. $6 \mathrm{w}$ VEGF: comparison of VEGF protein levels in the $6 \mathrm{wBC}, 6 \mathrm{wDM}$, and $6 \mathrm{wMP}$ groups. $12 \mathrm{w}$ VEGF: comparison of VEGF protein levels in the $12 \mathrm{wBC}$, $12 \mathrm{wDM}$, and $12 \mathrm{wMP}$ groups. DM VEGF: comparison of VEGF protein levels between the 6wDM and 12wDM groups. MP VEGF: comparison of VEGF protein levels between the 6wMP and 12wMP groups. 6wBC: 6-week blank control group. 6wDM: 6-week diabetic model group. 6wMP: 6-week medicine prophylaxis group. $12 \mathrm{wBC}$ : 12-week blank control group. 12wDM: 12-week diabetic model group. 12wMP: 12-week medicine prophylaxis group.

stimulates EC proliferation and migration, resulting in the formation of new sciatic nerve tissue.

At 6 weeks, the damage to the sciatic nerves was slight; thus, the rats showed no significant differences in thermal sensation or sciatic nerve conduction velocity. However, the sciatic nerves of the diabetic rats suffered ischemia and hypoxia, and VEGF was adaptively upregulated in a manner that depended on activated HIF- $1 \alpha$. Thus, compared to those of the $6 \mathrm{wBC}$ group, the sciatic nerves of the diabetic rats expressed more HIF- $1 \alpha$ and VEGF protein; however, this upregulation was transient. The $12 \mathrm{wDM}$ rats exhibited very low levels of HIF- $1 \alpha$ protein and less VEGF protein than the $6 \mathrm{wDM}$ rats due to the insufficient protective effect of activated HIF- $1 \alpha$ against long-term hypoxia; this deficiency leads to apoptosis, which may have contributed to the abnormal thermal sensation and sciatic nerve conduction velocity [5]. Comparisons between the $6 \mathrm{wMP}$ and $6 \mathrm{wDM}$ groups and between the $6 \mathrm{wMP}$ and $12 \mathrm{wMP}$ groups revealed that the HIF- $1 \alpha$ and VEGF protein levels in the sciatic nerves of the $6 \mathrm{wMP}$ rats were lower than those in the $6 \mathrm{wDM}$ rats and were in a rising stage. The sciatic nerves of the $6 \mathrm{wMP}$ rats experienced less severe ischemia and hypoxia than the $6 \mathrm{wDM}$ rats, which we attribute to the effects of TDFE.
By 12 weeks, the sciatic nerves of the diabetic rats were obviously injured, as can easily occur with the development of diabetes. The nerves of the $12 \mathrm{wDM}$ group were more severely damaged than those of the $12 \mathrm{wMP}$ group. A reduction in HIF$1 \alpha$ protein decreases the expression of genes that are activated by HIF-1, as demonstrated by the expression of VEGF in the $12 \mathrm{wDM}$ rats. Low VEGF expression is closely related to DPN [21] and is one of the reasons for the differences in thermal sensation and nerve conduction velocity among the $12 \mathrm{w}$ rats. In contrast, the $12 \mathrm{wMP}$ rats exhibited high levels of HIF-1 $\alpha$ and VEGF protein, which protected the sciatic nerves against diabetes-induced degeneration. The enhanced expression of VEGF improved the reduced thermal sensation, the decrease in nerve conduction velocity, and the obstacle of vascular regeneration [22]. This result supports our hypothesis.

The results from the $12 \mathrm{w}$ rats and $6 \mathrm{w}$ rats are not contradictory. During the early stages of diabetes, HIF- $1 \alpha$ and VEGF are signals that respond to the degree of tissue ischemia and hypoxia. Lower levels of HIF- $1 \alpha$ and VEGF indicate milder ischemia and hypoxia of the sciatic nerves. However, when the disease is advanced, the body is no longer able to compensate. Decreased VEGF leads to decreased function and recruitment of circulating angiogenic cells, injured sciatic 

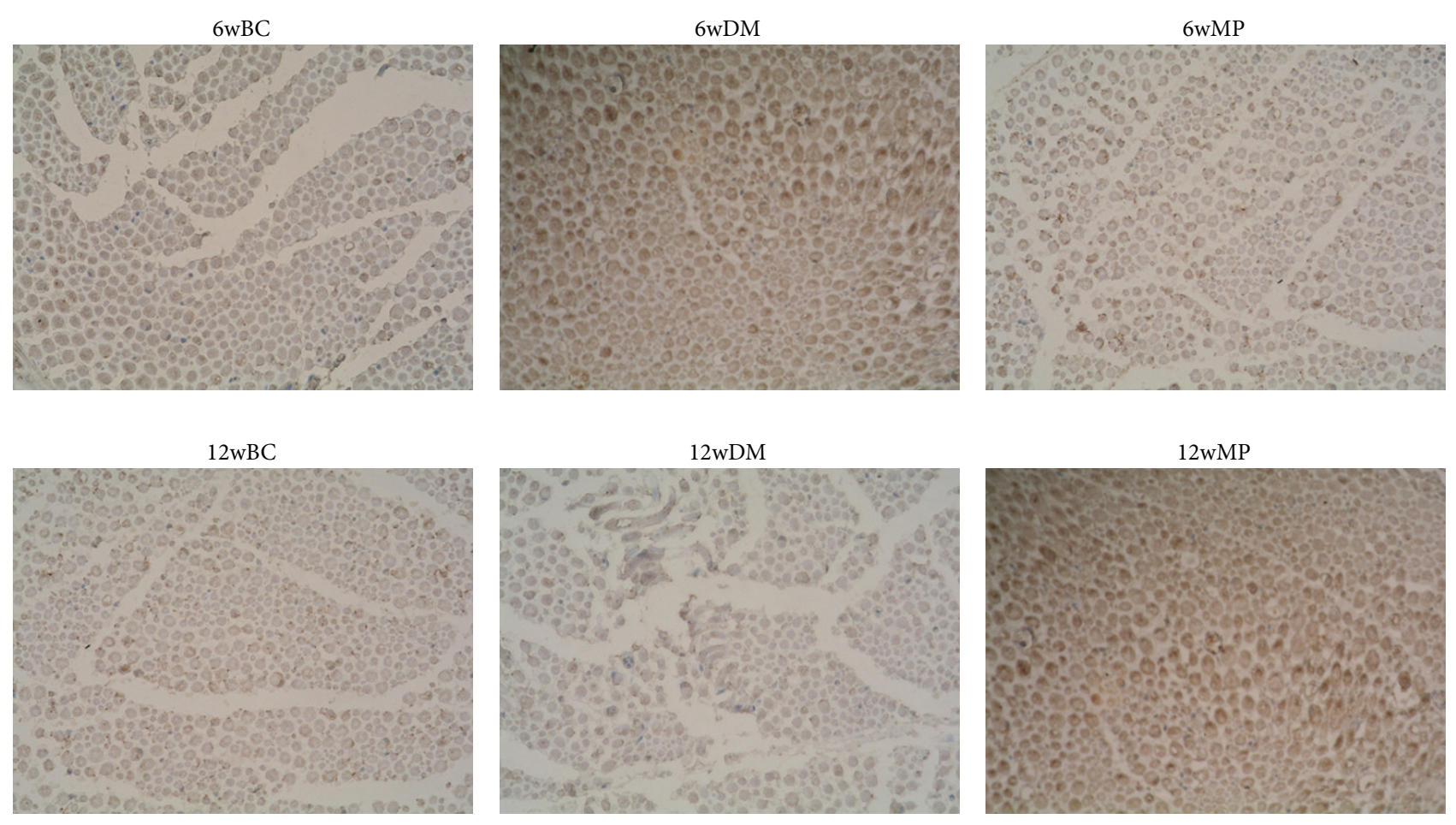

FIGURE 6: Photomicrographs of VEGF expression in the sciatic nerve tissue. Original magnification: $\times 400.6 \mathrm{wBC}$ : 6-week blank control group. 6wDM: 6-week diabetic model group. 6wMP: 6-week medicine prophylaxis group. 12wBC: 12-week blank control group. 12wDM: 12-week diabetic model group. 12wMP: 12-week medicine prophylaxis group.

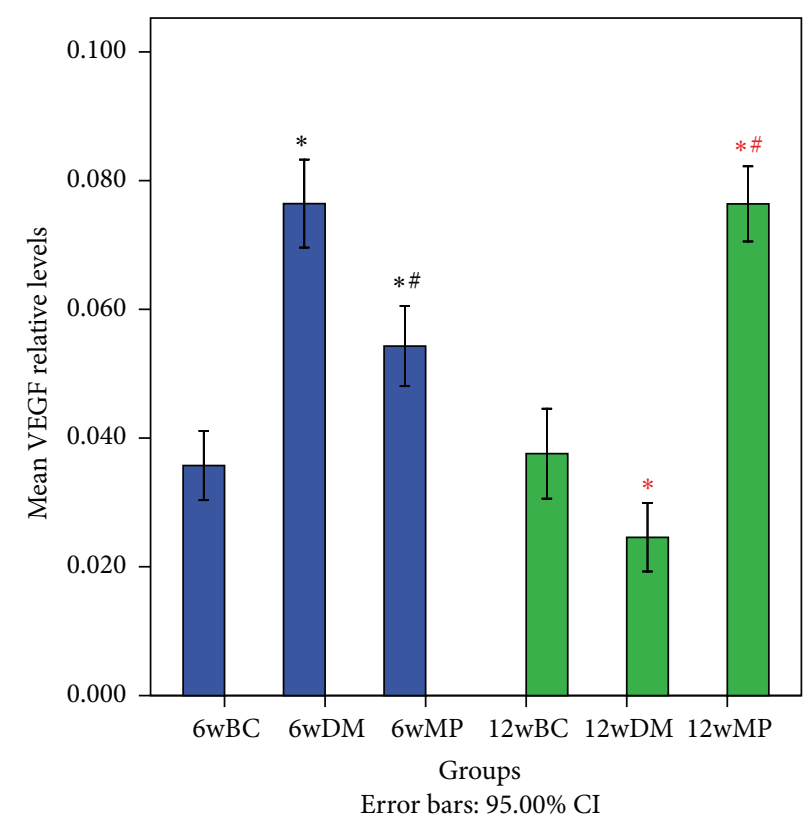

Tests of VEGF

6w VEGF

12w VEGF

FIGURE 7: Immunohistochemical analysis of VEGF in the sciatic nerves of the rats. ${ }^{*} P<0.05$ versus the 6 wBC group. ${ }^{\#} P<0.05$ versus the $6 \mathrm{wDM}$ group. ${ }^{*} P<0.05$ versus the $12 \mathrm{wBC}$ group. ${ }^{\#} P<0.05$ versus the $12 \mathrm{wDM}$ group. $6 \mathrm{w}$ VEGF: comparison of VEGF expression in the sciatic nerves of rats in the $6 \mathrm{wBC}, 6 \mathrm{wDM}$, and $6 \mathrm{wMP}$ groups. 12w VEGF: comparison of VEGF expression in the sciatic nerves of rats in the $12 \mathrm{wBC}$, $12 \mathrm{wDM}$, and 12wMP groups. 6wBC: 6-week blank control group. 6wDM: 6-week diabetic model group. 6wMP: 6-week medicine prophylaxis group. 12wBC: 12-week blank control group. 12wDM: 12-week diabetic model group. 12wMP: 12-week medicine prophylaxis group. 
$6 \mathrm{wBC}$

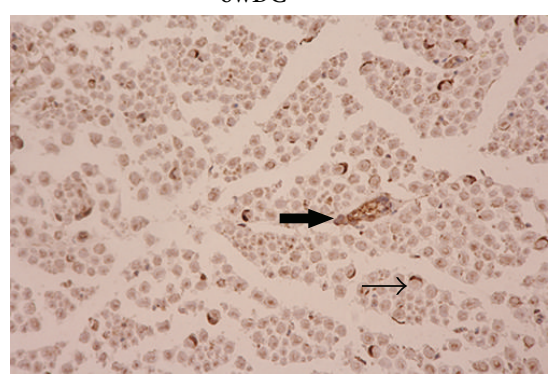

$12 \mathrm{wBC}$

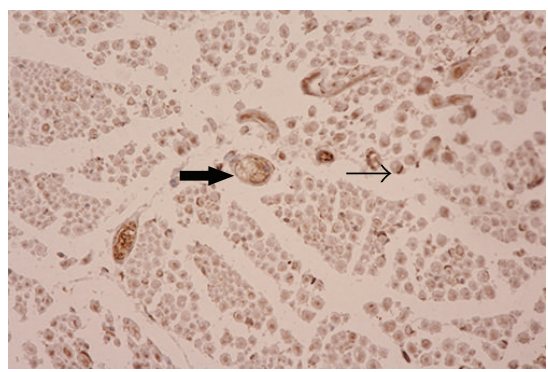

$6 \mathrm{wDM}$

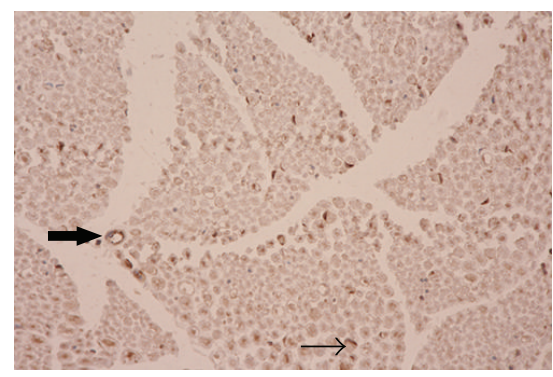

$12 \mathrm{wDM}$

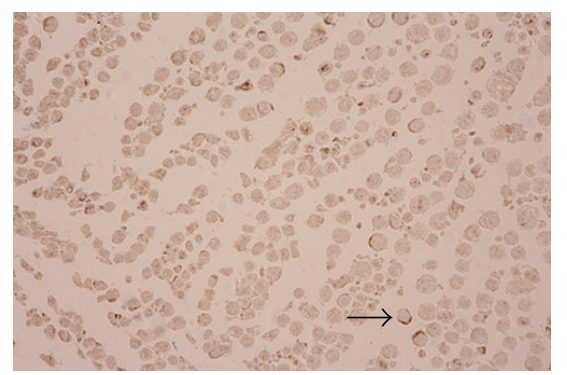

$6 \mathrm{WMP}$

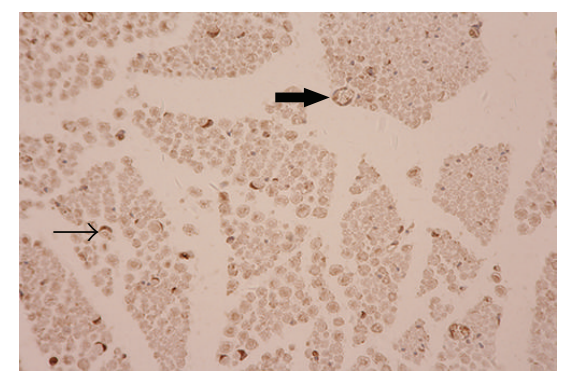

$12 \mathrm{wMP}$

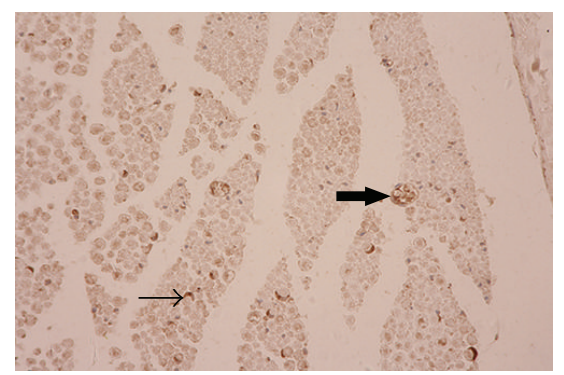

FIGURE 8: Photomicrographs of vWF expression in the sciatic nerve tissue. Original magnification: $\times 400$. vWF is found on the endoneurial (small arrow) and epineurial (large arrow) vessels. 6wBC: 6-week blank control group. 6wDM: 6-week diabetic model group. 6wMP: 6week medicine prophylaxis group. 12wBC: 12-week blank control group. 12wDM: 12-week diabetic model group. 12wMP: 12-week medicine prophylaxis group.

nerves, and the poor growth, proliferation, and adhesion of endothelial cells $[23,24]$. HIF- $1 \alpha$ and VEGF become manifestations of the ability to resist ischemia/hypoxia and to form new blood vessels. Increased levels of HIF- $1 \alpha$ and VEGF lessen the severity of ischemia and hypoxia of the sciatic nerves. In terms of protein expression levels, the results obtained in the $6 \mathrm{w}$ and $12 \mathrm{w}$ rats led us to the same conclusion: TDFE was able to relieve the ischemia and hypoxia of the sciatic nerves, suggesting that TDFE can prevent the development of DPN, reducing injury to the sciatic nerves in diabetic rats.

HIF- $1 \alpha$ was regulated at the post-mRNA level during the first six weeks. However, the expression of HIF- $1 \alpha$ mRNA differed between the groups by 12 weeks. Due to long-term low blood perfusion and the low-oxygen environment, the partial oxygen pressure of the sciatic nerve remained low, with a small degree of variation. This further damaged the sensitivity of the sciatic nerves to hypoxia. Thus, the HIF- $1 \alpha$ mRNA levels in the sciatic nerves of the $12 \mathrm{wDM}$ rats were even lower than those in the $12 \mathrm{wBC}$ rats. Surprisingly, the highest HIF-1 $\alpha$ mRNA levels occurred in the sciatic nerves of the 12 wMP rats. Many studies [25-27] have indicated that the hypoxia-induced increase in HIF- $1 \alpha$ occurs at the protein level, with no change in the mRNA level. Thus, this study suggests that the upregulation of HIF- $1 \alpha$ mRNA in the sciatic nerves of the $12 \mathrm{wMP}$ rats was very likely to be related to the application of TDFE. We can also conclude that TDFE can increase HIF- $1 \alpha$ mRNA levels. Increased HIF- $1 \alpha$ mRNA provides greater protection for sciatic nerves by increasing the levels of HIF- $1 \alpha$ and VEGF protein.

According to Traditional Chinese Medicine (TCM) theory, long-term diabetes results in deficiencies of Yin, Yang, Qi, and Xue, causing blood stasis and the blockage of meridians (alterations in the blood circulation and afflux to organs and tissues), which plays an important role in the etiology and pathogenesis of DPN [28]. Zhang Zhongjing from the Han Dynasty discussed TDFE in his work called "Treatise on Exogenous Febrile Disease," in which he suggested that TDFE affected the warming and dredging meridians (passages through which vital energy circulates). This effect is similar to what we would now describe as increasing blood flow. Zhang Zhongjing maintained that "Algid extremities, faint pulses, and Tangkuei Decoction for Frigid Extremities are needed.” Xu Hong from the Ming Dynasty proposed another explanation that "deficiencies of Yin and Xue result in feeble pulses and deficiencies of Yang and Qi cause algid extremities. Angelicae Sinensis (TCN: Danggui) is used to enrich the Xue. Radix Paeonia Alba (TCN: Baishao) is used to nourish Ying Qi. Cassia Twig (TCN: Guizhi) and Asarum sieboldii Mig (TCN: Xixin) are used to disperse cold. Radix liquiritiae (TCN: Gancao), Akebia quinata Decne. (TCN: Mutong), and Fructus Ziziphi Jujubae (TCN: Dazao) were used as assist medicine." Thus, the effects of TDFE fit well with the TCM theory of the pathogenesis of DPN. TDFE can enrich Yin and Xue, invigorate meridians, facilitate Yang and Qi, warm extremities, and recover fine pulses. 


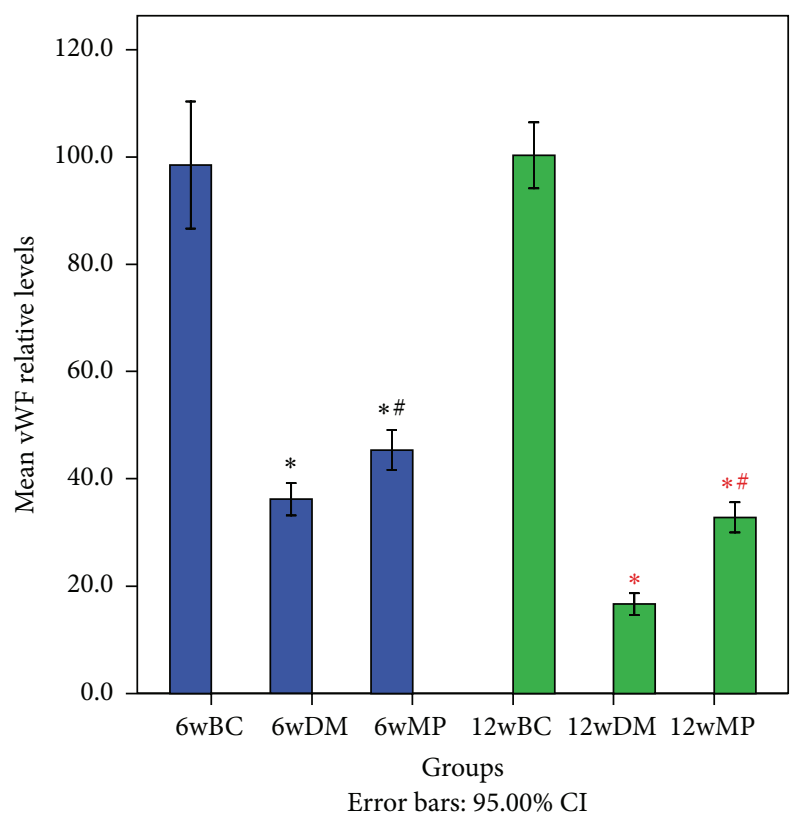

$$
\begin{aligned}
& \text { Tests of vWF } \\
& \square 6 \mathrm{w} v W F \\
& \square 12 \mathrm{w} v W F
\end{aligned}
$$

FIGURE 9: Immunohistochemical analysis of vWF in the sciatic nerves of the rats. ${ }^{*} P<0.05$ versus the $6 \mathrm{wBC}$ group. ${ }^{*} P<0.05$ versus the $6 \mathrm{wDM}$ group. ${ }^{*} P<0.05$ versus the $12 \mathrm{wBC}$ group. ${ }^{\#} P<$ 0.05 versus the $12 \mathrm{wDM}$ group. $6 \mathrm{w}$ vWF: comparison of the vWF expression in the sciatic nerves of rats in the $6 \mathrm{wBC}, 6 \mathrm{wDM}$, and $6 \mathrm{wMP}$ groups. $12 \mathrm{w} \mathrm{vWF}$ : comparison of the vWF expression among the sciatic nerves of rats from $12 \mathrm{wBC}, 12 \mathrm{wDM}$, and $12 \mathrm{wMP}$. $6 \mathrm{wBC}$ : 6-week blank control group. 6wDM: 6-week diabetic model group. 6wMP: 6-week medicine prophylaxis group. $12 \mathrm{wBC}$ : 12 -week blank control group. 12wDM: 12-week diabetic model group. 12wMP: 12week medicine prophylaxis group.

TDFE is a classic TCM prescription; it has been used for warming and dredging meridians for more than one thousand years, and its efficacy is unquestionable. In the present study, early preventive administration of TDFE relieved the ischemia and hypoxia of sciatic nerves and maintained thermal sensation and nerve conduction velocity. As the DPN progressed, this preventive effect became increasingly obvious. In addition, the application of TDFE for 12 weeks could protect the sciatic nerves of the diabetic rats by increasing the expression of HIF- $1 \alpha$ mRNA. However, analysis of the chemical composition of TDFE and studies of other peripheral nerves are still required. In addition, the specific mechanism by which TDFE regulates the levels of HIF- $1 \alpha$ mRNA remains unclear.

\section{Disclosure}

Pengsong Liu and Yuanyuan Bian are joint senior authors.

\section{Conflict of Interests}

The authors declare that there is no conflict of interests regarding the publication of this paper.

\section{Authors' Contribution}

Aiming Jia, Hong Zhang, Pengsong Liu, and Yuanyuan Bian conceived and designed the experiments. Yuanyuan Bian and Pengsong Liu performed the experiments. Pengsong Liu and Yuanyuan Bian analyzed the data. Yuanyuan Bian, Aiming Jia, Hong Zhang, and Pengsong Liu contributed to reagents, materials, and analysis tools. Pengsong Liu and Yuanyuan Bian wrote the paper. Aiming Jia provided critical comments for amendments of the paper.

\section{Acknowledgments}

The electrophysiological testing was supported in part by Lei Fu from Functional Lab, Dalian Medical University, Dalian, Liaoning, China. The authors gratefully acknowledge the syntactic support of Yang Yu from the English Teaching and Research Section, Dalian Medical University, Dalian, Liaoning, China.

\section{References}

[1] A. Peltier, S. A. Goutman, and B. C. Callaghan, "Painful diabetic neuropathy," British Medical Journal, vol. 348, Article ID g1799, 2014.

[2] W. Chen, Y. Zhang, X. Li, G. Yang, and J. P. Liu, "Chinese herbal medicine for diabetic peripheral neuropathy," Cochrane Database of Systematic Reviews, vol. 10, Article ID CD007796, 2013.

[3] L. Guo, F. Jiang, Y.-T. Tang, M.-Y. Si, and X.-Y. Jiao, “The association of serum vascular endothelial growth factor and ferritin in diabetic microvascular disease," Diabetes Technology and Therapeutics, vol. 16, no. 4, pp. 224-234, 2014.

[4] C. Zheng, W. Ou, H. Shen, Z. Zhou, and J. Wang, "Combined therapy of diabetic peripheral neuropathy with breviscapine and mecobalamin: a systematic review and a meta-analysis of Chinese studies," BioMed Research International, vol. 2015, Article ID 680756, 11 pages, 2015.

[5] J. C. Chavez, K. Almhanna, and L. N. Berti-Mattera, "Transient expression of hypoxia-inducible factor- 1 alpha and target genes in peripheral nerves from diabetic rats," Neuroscience Letters, vol. 374, no. 3, pp. 179-182, 2005.

[6] K. Sarkar, K. Fox-Talbot, C. Steenbergen, M. Bosch-Marcë, and G. L. Semenza, "Adenoviral transfer of HIF-1 $\alpha$ enhances vascular responses to critical limb ischemia in diabetic mice," Proceedings of the National Academy of Sciences of the United States of America, vol. 106, no. 44, pp. 18769-18774, 2009.

[7] C. Loenarz, M. L. Coleman, A. Boleininger et al., "The hypoxiainducible transcription factor pathway regulates oxygen sensing in the simplest animal, Trichoplax adhaerens," The EMBO Reports, vol. 12, no. 1, pp. 63-70, 2011.

[8] G. L. Semenza, "Hypoxia-inducible factors in physiology and medicine," Cell, vol. 148, no. 3, pp. 399-408, 2012.

[9] X. Xin, M. Rodrigues, M. Umapathi et al., "Hypoxic retinal Müller cells promote vascular permeability by HIF-1dependent up-regulation of angiopoietin-like 4," Proceedings of the National Academy of Sciences of the United States of America, vol. 110, no. 36, pp. E3425-E3434, 2013.

[10] C. Wang, Y. Cai, Y. Zhang, Z. Xiong, G. Li, and L. Cui, "Local injection of deferoxamine improves neovascularization 
in ischemic diabetic random flap by increasing HIF- $1 \alpha$ and VEGF expression," PLoS ONE, vol. 9, no. 6, Article ID e100818, 2014.

[11] H.-F. Ji, X.-J. Li, and H.-Y. Zhang, "Natural products and drug discovery: can thousands of years of ancient medical knowledge lead us to new and powerful drug combinations in the fight against cancer and dementia?" EMBO Reports, vol. 10, no. 3, pp. 194-200, 2009.

[12] W. Chen, Y.-F. Luo, and J.-P. Liu, "Topical herbal medicine for treatment of diabetic peripheral neuropathy: a systematic review of randomized controlled trials," Forschende Komplementärmedizin, vol. 18, no. 3, pp. 134-145, 2011.

[13] C.-Z. Hao, F. Wu, L. Lu et al., "Chinese herbal medicine for diabetic peripheral neuropathy: an updated meta-analysis of 10 high-quality randomized controlled studies," PLoS ONE, vol. 8, no. 10, Article ID e76113, 2013.

[14] D. Selvarajah, T. Cash, J. Davies et al., "SUDOSCAN: a simple, rapid, and objective method with potential for screening for diabetic peripheral neuropathy," PLoS ONE, vol. 10, no. 10, Article ID e0138224, 2015.

[15] H.-P. Yao, W.-Y. Feng, Y.-X. Wei et al., "Methodology of the determination of sciatic nerve conduction velocity in rats," China Pharmacy, vol. 22, no. 1, pp. 18-20, 2011.

[16] C. F. Bento and P. Pereira, "Regulation of hypoxia-inducible factor 1 and the loss of the cellular response to hypoxia in diabetes," Diabetologia, vol. 54, no. 8, pp. 1946-1956, 2011.

[17] J. E. Sadler, "Biochemistry and genetics of von Willebrand factor," Annual Review of Biochemistry, vol. 67, pp. 395-424, 1998.

[18] K. A. Gallagher, Z.-J. Liu, M. Xiao et al., "Diabetic impairments in NO-mediated endothelial progenitor cell mobilization and homing are reversed by hyperoxia and SDF-1 $\alpha$," Journal of Clinical Investigation, vol. 117, no. 5, pp. 1249-1259, 2007.

[19] D. J. Ceradini, D. Yao, R. H. Grogan et al., "Decreasing intracellular superoxide corrects defective ischemia-induced new vessel formation in diabetic mice," The Journal of Biological Chemistry, vol. 283, no. 16, pp. 10930-10938, 2008.

[20] A. Cattin, J. Burden, L. Van Emmenis et al., "Macrophageinduced blood vessels guide schwann cell-mediated regeneration of peripheral nerves," Cell, vol. 162, no. 5, pp. 1127-1139, 2015.

[21] B. Wirostko, T. Y. Wong, and R. Simó, "Vascular endothelial growth factor and diabetic complications," Progress in Retinal and Eye Research, vol. 27, no. 6, pp. 608-621, 2008.

[22] P. Schratzberger, D. H. Walter, K. Rittig et al., "Reversal of experimental diabetic neuropathy by VEGF gene transfer," Journal of Clinical Investigation, vol. 107, no. 9, pp. 1083-1092, 2001.

[23] G. P. Fadini, S. Sartore, M. Schiavon et al., "Diabetes impairs progenitor cell mobilisation after hindlimb ischaemiareperfusion injury in rats," Diabetologia, vol. 49, no. 12, pp. 3075-3084, 2006.

[24] L. Liu, G. P. Marti, X. Wei et al., "Age-dependent impairment of HIF- $1 \alpha$ expression in diabetic mice: correction with electroporation-facilitated gene therapy increases wound healing, angiogenesis, and circulating angiogenic cells," Journal of Cellular Physiology, vol. 217, no. 2, pp. 319-327, 2008.

[25] W. Moritz, F. Meier, D. M. Stroka et al., "Apoptosis in hypoxic human pancreatic islets correlates with HIF-lalpha expression," The FASEB Journal, vol. 16, no. 7, pp. 745-747, 2002.
[26] R. H. Wenger, I. Kvietikova, A. Rolfs, M. Gassmann, and H. H. Marti, "Hypoxia-inducible factor- $1 \alpha$ is regulated at the postmRNA level," Kidney International, vol. 51, no. 2, pp. 560-563, 1997.

[27] L. E. Huang, Z. Arany, D. M. Livingston, and H. Franklin Bunn, "Activation of hypoxia-inducible transcription factor depends primarily upon redox-sensitive stabilization of its $\alpha$ subunit," Journal of Biological Chemistry, vol. 271, no. 50, pp. 32253-32259, 1996.

[28] Y. Piao and X. Liang, "Chinese medicine in diabetic peripheral neuropathy: experimental research on nerve repair and regeneration," Evidence-Based Complementary and Alternative Medicine, vol. 2012, Article ID 191632, 13 pages, 2012. 


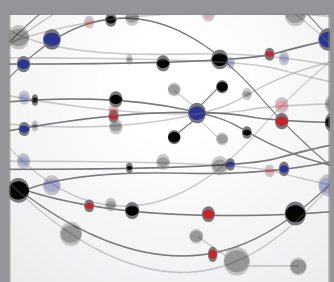

The Scientific World Journal
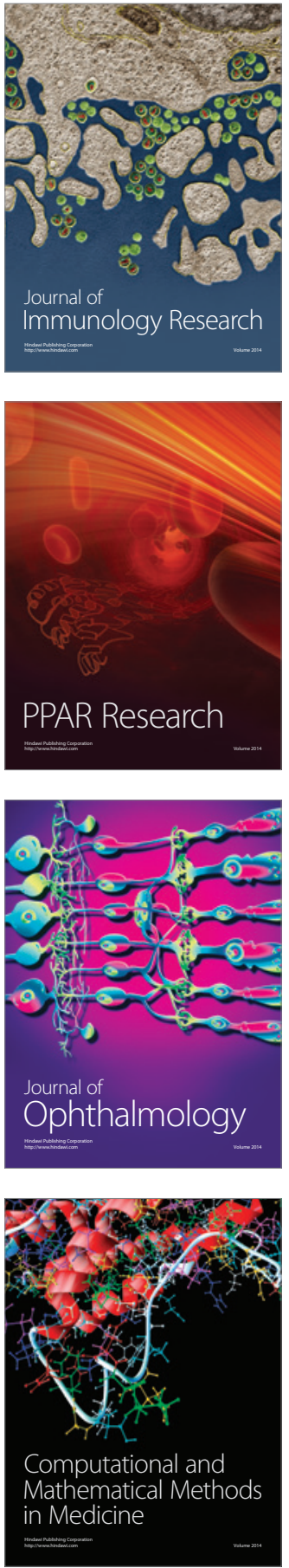

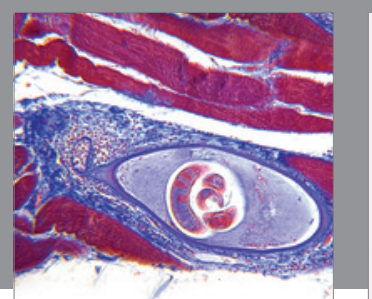

Gastroenterology Research and Practice

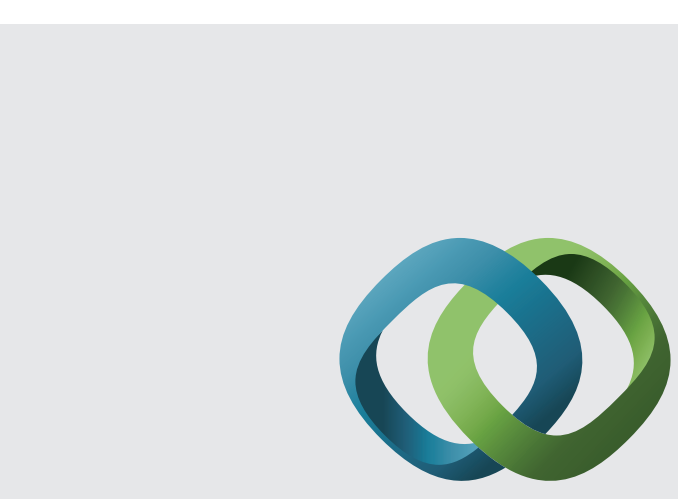

\section{Hindawi}

Submit your manuscripts at

http://www.hindawi.com
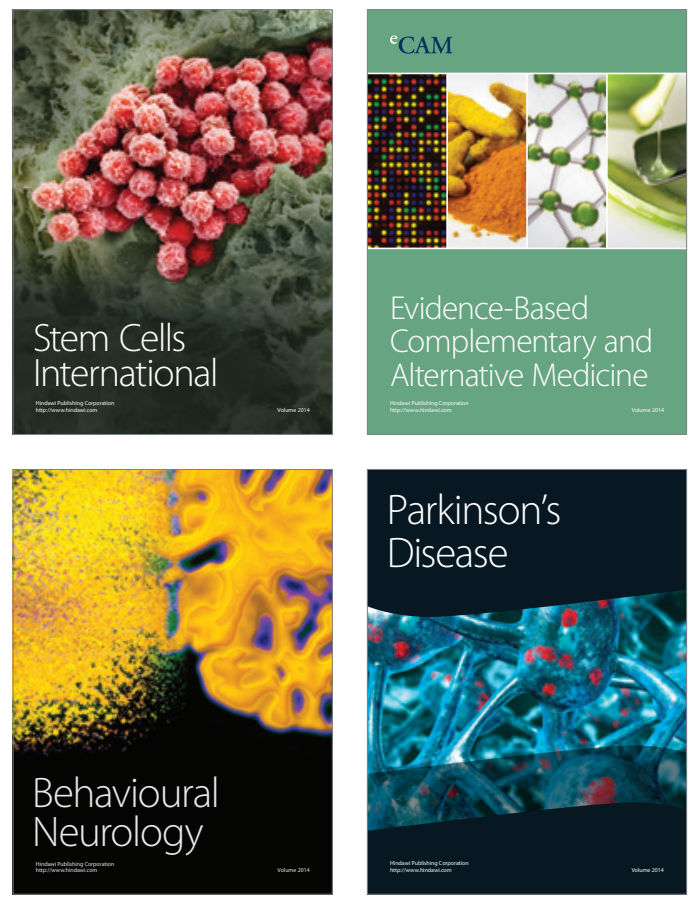
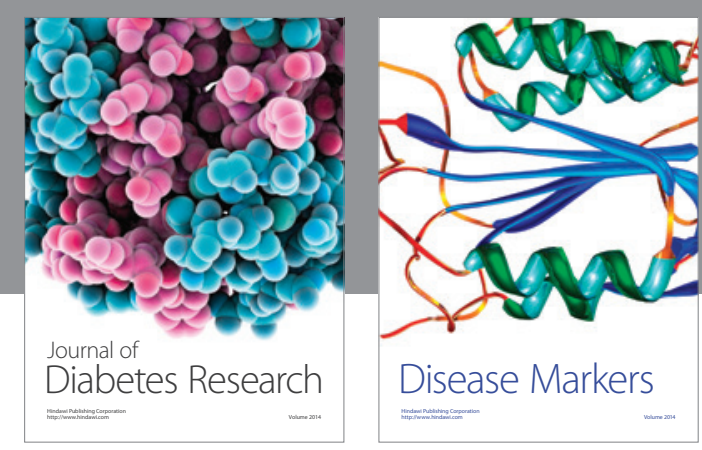

Disease Markers
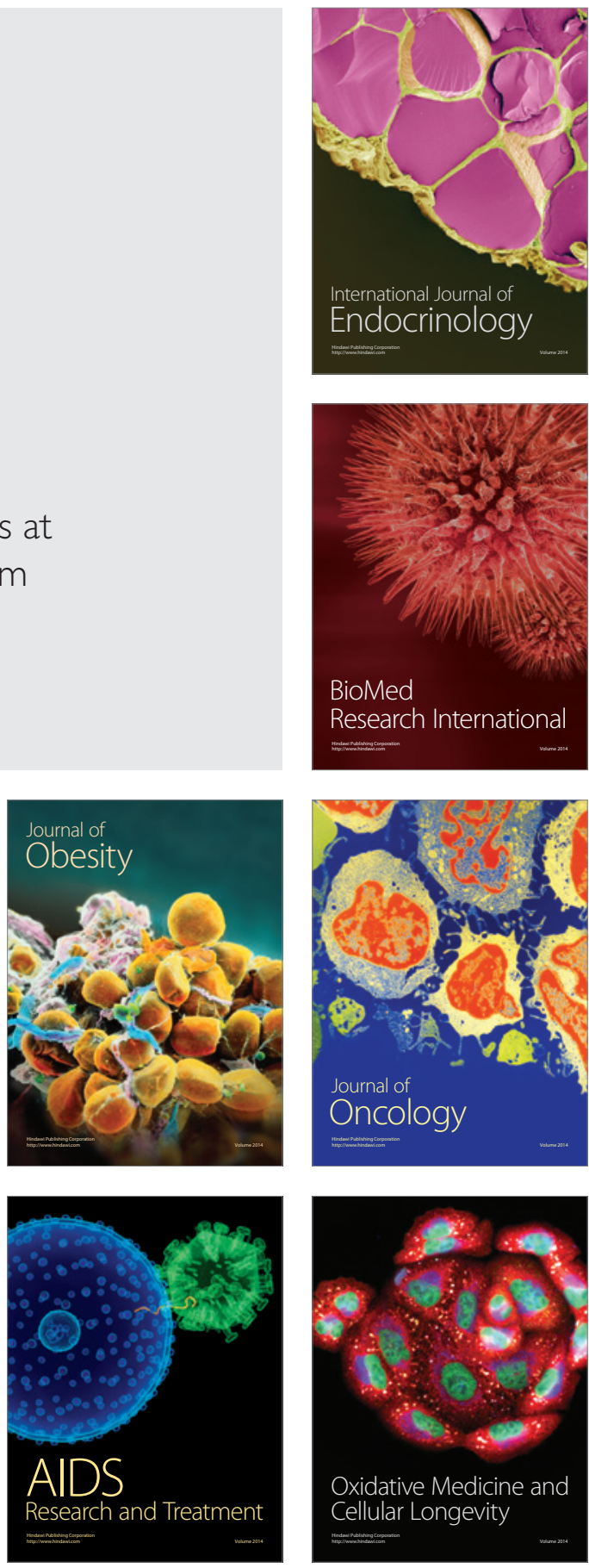